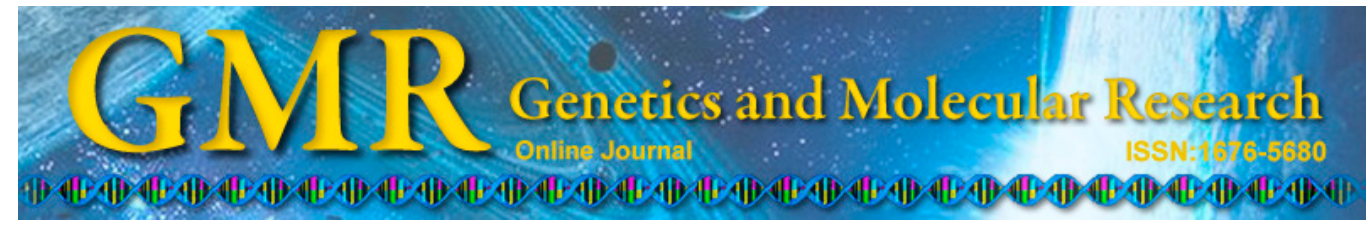

\title{
Study of optimal scheme of spinal image-guided radiotherapy based on expression of caspase-3 in spinal cord neurons by orthogonal design
}

\author{
W.L. Xu, J.L.T. Tayerjiang, X.B. Zhao, H. Wang, Q. Wang and H. Yuan \\ Department of Bone Surgery 1, \\ People's Hospital of Xinjiang Uygur Autonomous Region, Urumqi, China \\ Corresponding author: H. Yuan \\ E-mail: JingpingBAIcn@163.com
}

Genet. Mol. Res. 14 (2): 3223-3233 (2015)

Received January 6, 2014

Accepted May 5, 2014

Published April 13, 2015

DOI http://dx.doi.org/10.4238/2015.April.13.1

\begin{abstract}
The aim of the study was to optimize the biological safety scheme of spinal image-guided radiotherapy (IGRT) by determining the expression of caspase-3 in spinal cord neurons after IGRT. Thirty-six adult male beagles were assigned according to a random number table and subjected to IGRT to the 7th-12th canine thoracic vertebral bodies under a total dose of 80 Gy over 5 weeks. An immunohistochemical method was used to detect the expression of caspase-3 protein in spinal cord tissues, and real-time quantitative RT-PCR with SYBR Green I was used to detect the expression of caspase-3 mRNA in spinal cord tissues. Analysis of the orthogonal experiment results showed that caspase- 3 expression in the spinal cord neurons was lowest when a single dose of 16 Gy was applied at a dose rate of $4 \mathrm{~Gy} / \mathrm{min}$, and field number of 9 , with ray angle being equal. Thus, spinal IGRT showed high biological safety, and the best radiotherapy scheme for biological safety was single dose of 16 Gy at $4 \mathrm{~Gy} / \mathrm{min}$, with 9 fields and equal ray angle.
\end{abstract}

Key words: Image-guided radiotherapy; Spinal cord neuron; Caspase-3; Spinal biological safety; Orthogonal experiment 


\section{INTRODUCTION}

Currently, the control and treatment effect of spinal tumors is still not satisfactory. In recent years, image-guided radiotherapy (IGRT) has been widely used in clinical practice in tumor radiotherapy on account of its remarkable physical advantages (Tsai et al., 2009). IGRT of the spine is a four-dimensional radiation therapy technology, where a time factor is added to three-dimensional radiotherapy technology. It fully considers the motion of the spinal metastatic tumor during treatment and the displacement error of the fractionated therapy, such as with breathing and peristaltic movement, daily setup error, target area contraction caused by change of dose distribution and the influence on the treatment scheme and other aspects of the situation. Advanced imaging equipment is used in patients before and during treatment, real-time monitoring of the spinal metastases and spinal cord, where it is possible to adjust treatment conditions according to the organ position, which enables the irradiation field "to follow" the spinal metastases closely, and achieve accurate radiotherapy for spinal, simultaneously implementing radical radiotherapy and avoiding radiation injury to normal tissue, making it a relatively ideal treatment method (Gerszten and Burton, 2008). But the clinical application of intensity-modulated radiotherapy is relatively new, the spinal anatomy is complex, and there are so many factors that influence the spinal IGRT scheme, which can greatly reduce spinal biological safety (Xilin et al., 2009).

Hence, this study, based on fundamental animal research and using the orthogonal principle, aimed to optimize the spinal IGRT scheme by determining spinal biological safety after IGRT.

\section{MATERIAL AND METHODS}

\section{Experimental animals}

This experiment was a random, orthogonal design animal experiment, which was carried out in the Key Laboratory of Xinjiang Medical University Affiliated Tumor Hospital from January 2012 to January 2013. The experiment was approved by the animal Ethics Committee of the Tumor Hospital (No. 20110301A41).

Thirty-six adult male beagles, aged 1 to 1.5 years, weighing $12 \pm 1.5 \mathrm{~kg}$, and $60 \pm 5 \mathrm{~cm}$ in length, were provided by the Experimental Animal Research Academy of Medical Sciences, Sichuan Province (license No. SCXK 2004-15). The dogs were housed in single cages and given complete feed and clean water. Environmental temperature was $20^{\circ}-23^{\circ} \mathrm{C}$ and relative humidity $40-60 \%$, conditions ensuring adequate sleep. The handling of experimental animals was in accordance with the requirements of the "guidance on well-being of laboratory animals", which was promulgated by the Ministry of Science and Technology of the People's Republic of China (2006).

\section{Number of experimental animals}

According to an L12 (3 x 23) orthogonal experiment (Table 1), requiring 12 beagles and 3 repeated experiments, the experiment included 36 beagles; each dog was subjected to IGRT at the 7th-12th thoracic level and every group was given a total radiotherapy dose of $80 \mathrm{~Gy}$.

\section{Analysis of experimental factors and levels}

The 5th, 7th, 9th radiation fields and 3 levels were as follows: fractional dose $1.8 \mathrm{~Gy}$, 


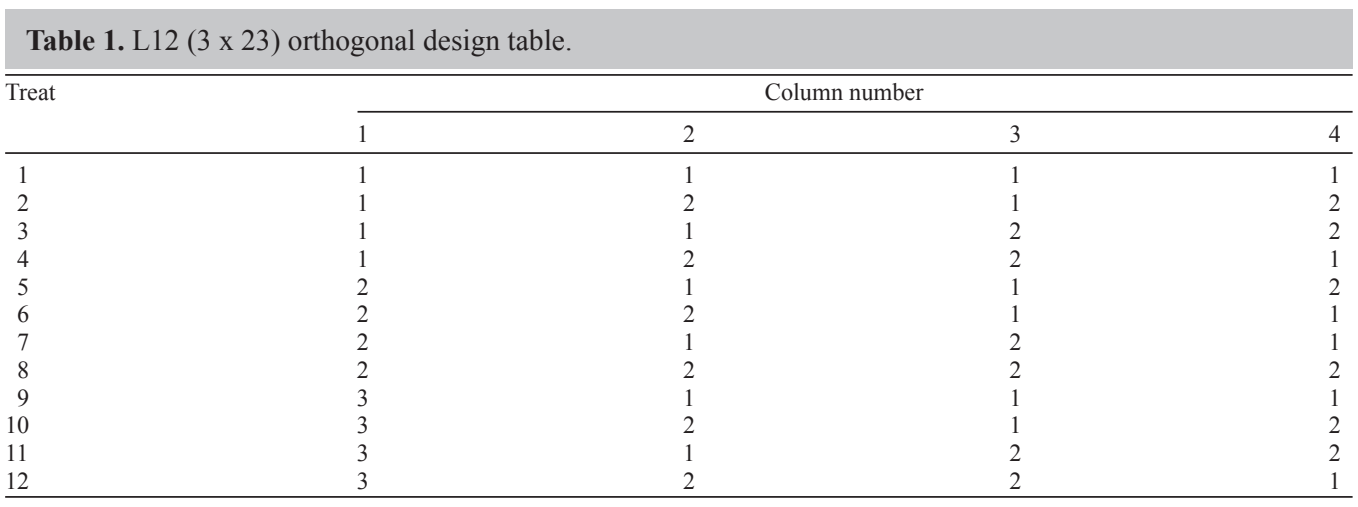

Table 2. Influence factors and levels of canine spinal image-guided radiotherapy.
\begin{tabular}{lcccl}
\hline Level & \multicolumn{4}{c}{ Factor } \\
\cline { 2 - 5 } & Radiation field number (field) (A) & Each radiation dose (Gy) (B) & Dose rate (Gy/min) (C) & Radiation angle (D) \\
\hline 1 & 5 & 16 & 4 & Equal angle \\
2 & 7 & 20 & 6 & Unequal angle \\
3 & 9 & & & \\
\hline
\end{tabular}

2 Gy 2 levels; dose rate $6 \mathrm{~Gy} / \mathrm{min}, 9 \mathrm{~Gy} / \mathrm{min} 2$ levels; equal radiation angle, unequal radiation 2 levels (shown in Table 2).

\section{Radiotherapy intervention method}

Thirty-six beagles were grouped according to a random number table, and the 7th to 12th thoracic vertebral bodies were determined for spinal radiotherapy, aided by CT (Cleveland CT, Cleveland, $\mathrm{OH}, \mathrm{USA}$ ) and computer. The accurate radiation target area was delineated and the radiotherapy scheme was drafted (Table 3, Figure 1). The dogs were arranged on the canine fixed mold after intravenous anesthesia and subjected to IGRT scheduled for 5 weeks (on work days, not Saturday and Sunday). The dogs of fractional dose 20 Gy underwent radiotherapy once a week for a total of 4 weeks, and then still using the same anesthesia were given blank treatment in the 5 th week (to eliminate the system error of different fractional dose

\begin{tabular}{|c|c|c|c|c|c|}
\hline \multirow[t]{2}{*}{ Radiotherapy method number } & \multirow[t]{2}{*}{$\mathrm{N}$} & \multicolumn{4}{|c|}{ Factor } \\
\hline & & No. of radiation fields (field) & Radiation dose each time (Gy) & Dose rate $(\mathrm{Gy} / \mathrm{min})$ & Radiation angle \\
\hline 1 & 3 & 5 & 16 & 4 & Equal \\
\hline 2 & 3 & 5 & 20 & 4 & Unequal \\
\hline 3 & 3 & 5 & 16 & 6 & Equal \\
\hline 4 & 3 & 5 & 20 & 6 & Equal \\
\hline 5 & 3 & 7 & 16 & 4 & Unequal \\
\hline 6 & 3 & 7 & 20 & 4 & Equal \\
\hline 7 & 3 & 7 & 16 & 6 & Equal \\
\hline 8 & 3 & 7 & 20 & 6 & Unequal \\
\hline 9 & 3 & 9 & 16 & 4 & Equal \\
\hline 10 & 3 & 9 & 20 & 4 & Unequal \\
\hline 11 & 3 & 9 & 16 & 6 & Unequal \\
\hline 12 & 3 & 9 & 20 & 6 & Equal \\
\hline
\end{tabular}




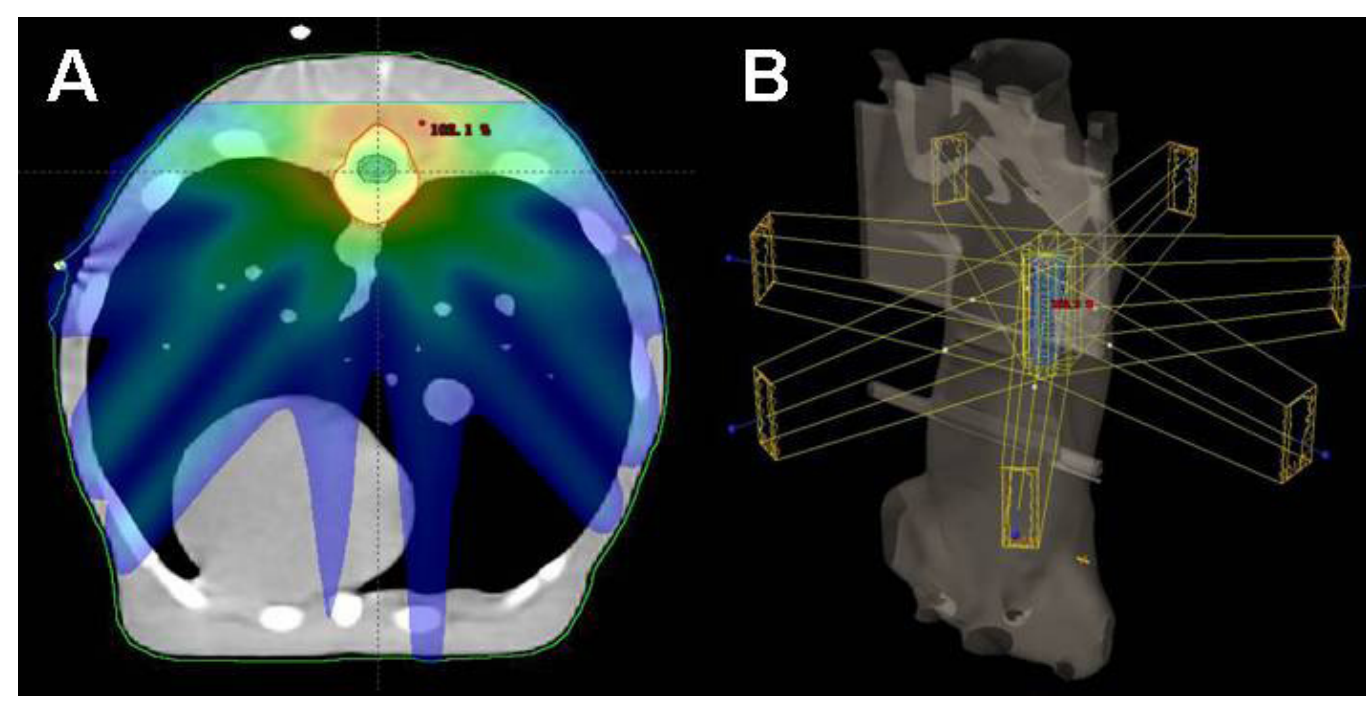

Figure 1. Accurate radiation target areas were delineated and radiotherapy schemes were drafted. A. CT scanning graph. B. Radiotherapy scheme of radiation target area.

groups). In 5 weeks, the 36 dogs were subjected to spinal IGRT on 7th-12th thoracic vertebral bodies.

\section{Sampling and pretreatment in 7th-12th segments of thoracic spinal cord}

The beagle dogs were killed under anesthesia at the end of 3 months after radiotherapy, and the 7th-12th segments of the thoracic spinal cord were removed under a microscope. A portion of the spinal cord tissue was fixed with $10 \%$ formaldehyde and embedded in paraffin, and afterwards $4-\mu \mathrm{m}$ sections were prepared for immunohistochemistry. A portion of the spinal cord tissue was quick-frozen in liquid nitrogen and preserved in a $-86^{\circ} \mathrm{C}$ freezer for total RNA extraction.

\section{Expression of caspase-3 protein in the spinal cord tissue detected by immunohistochemical staining}

The SABC method was used for immunohistochemical staining (Manorajan et al., 2010). The paraffin sections were dewaxed, rehydrated, and subjected to immunohistochemical assay according to the SABC kit, with the first antibody being rabbit anti-canine monoclonal antibody (Santa Cruz Biotechnology, Santa Cruz, CA, USA) $\left(1: 100,4^{\circ} \mathrm{C}, 2 \mathrm{~h}\right)$ and the second antibody rabbit anti-canine monoclonal antibody (Santa Cruz Biotechnology) (1:100, $37^{\circ} \mathrm{C}, 1 \mathrm{~h}$ ). The slides were examined under a light microscope (Leica, Wetzlar, Germany), and the BT-2000 color pathological image analysis system was applied. Ten fields were randomly selected from each of the two spinal anterior horn areas, the positive staining area were automatic measured, and the mean percentage of positive staining area in vision area was used as the expression quantity of caspase- 3 protein. 


\section{Expression of caspase-3 mRNA detected in spinal cord tissue by SYBR Green I real-time quantitative $\mathrm{RT}$-PCR}

Trizol reagent (Santa Cruz Biotechnology) was used to extract the RNA in different spinal cord tissues, which showed an $\mathrm{A}_{260} / \mathrm{A}_{280}$ ratio of 1.8-2.0. A 2- $\mu \mathrm{g}$ sample was used to carry out reverse transcription reaction, and DNA after reverse transcription, was detected by real-time quantitative PCR. The PCR mixture was $50 \mu \mathrm{L}$, with $1 \mu \mathrm{L}$ SYBR Green I reagent (Santa Cruz Biotechnology). The reaction conditions were as follows: $95^{\circ} \mathrm{C}$ for $2 \mathrm{~min}$ and 35 cycles of $94^{\circ} \mathrm{C}$ for $1 \mathrm{~min}, 58^{\circ} \mathrm{C}$ for $30 \mathrm{~s}$ and $72^{\circ} \mathrm{C}$ for $30 \mathrm{~s}$, with the temperature change rate set at $20^{\circ} \mathrm{C} / \mathrm{s}$, where the melting curve ranged $70^{\circ}-95^{\circ} \mathrm{C}$. During the PCR amplification process, the cycle number (threshold cycle, $\mathrm{Ct}$ ) corresponding to the inflection point was used as the detection critical point, in which the fluorescence signal increased from the background to the exponential growth phase. Real-time monitoring of the whole PCR process was through fluorescence signal accumulation, the cycle number observed or $\mathrm{Ct}$ value was recorded as the fluorescence signal in each reaction reaching the preset threshold. In the negative control, CDNA was not added to the reaction system, using deionized water to add up to a total volume of $50 \mu \mathrm{L}$, and 3 replicate tubes were used for each sample, where the mean value was taken as the $\mathrm{Ct}$ value. Relative quantitative analysis was used.

\section{Statistical analysis}

The above data were statistically evaluated using the SPSS 19.0 software package (SPSS, Chicago, IL, USA), and all data are reported as means \pm SD. Caspase-3 protein and mRNA in the spinal cord neurons were statistically analyzed by variation analysis of the orthogonal experiment, $\alpha=0.05$, where $\mathrm{P}<0.05$ was considered to be statistically significant.

\section{RESULTS}

\section{Expression of caspase-3 protein in 7th-12th segments of spinal cord tissues}

Caspase-3 positive products appeared reddish brown or brownish yellow, which were seen in the anterior horn of spinal cord neurons and localized in the cytoplasm of neurons and processes by subcellular localization. The nucleus was not stained or weakly stained.

Immunohistochemistry was used to detect the expression of caspase-3 protein in the spinal cord nerve cells of each experimental group of dogs, which showed that weakly positive expression of caspase- 3 protein was evident in a small amount of spinal cord neurons and that positive expression in spinal neurons was mainly centralized in the anterior horn of spinal cord and white matter (electron microscopy results shown in Figure 2).

Caspase-3 protein expression levels are shown in detail in Figure 2 and in each spinal cord neuron (Table 4), and the results were analyzed by ANOVA of the orthogonal experiment. (shown in Figure 2). 


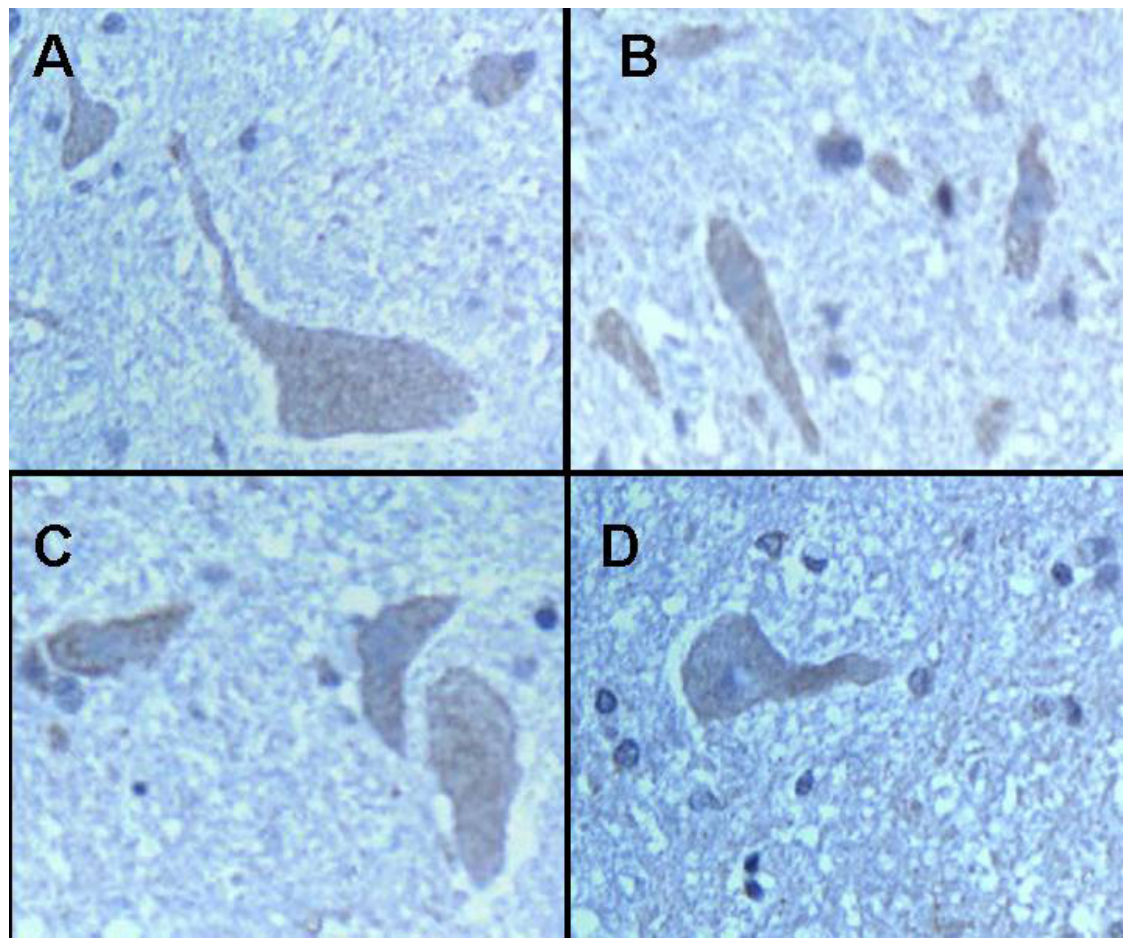

Figure 2. Expression of caspase-3 protein in the spinal cord tissue. A. Immunohistochemistry (caspase-3 400X) of No. 3 dog. B. Immunohistochemistry (caspase-3 400X) of No. 6 dog. C. Immunohistochemistry (caspase-3 400X) of No. 9 dog. D. Immunohistochemistry (caspase-3 400X) of No. 12 dog.

Table 4. Orthogonal experiment calculate table of expression of caspase-3 protein in spinal cord neurons results $(\%)$.

\begin{tabular}{|c|c|c|c|c|c|c|c|}
\hline Scheme number & $\begin{array}{c}\text { Radiation field } \\
\text { No. }\end{array}$ & $\begin{array}{c}\text { Fractional } \\
\text { No. }\end{array}$ & $\begin{array}{l}\text { Dose rate } \\
\text { (Gy/min) }\end{array}$ & Radiation No. & $\begin{array}{l}\text { First group } \\
\text { caspase-3 }\end{array}$ & $\begin{array}{l}\text { Second number } \\
\text { caspase- } 3\end{array}$ & $\begin{array}{c}\text { Third number } \\
\text { caspase- } 3\end{array}$ \\
\hline 1 & 5 & 16 & 4 & Equal angle & 4.34 & 4.41 & 4.43 \\
\hline 2 & 5 & 20 & 4 & Unequal angle & 4.91 & 5.00 & 5.18 \\
\hline 3 & 5 & 16 & 6 & Unequal angle & 4.71 & 4.73 & 4.75 \\
\hline 4 & 5 & 20 & 6 & Equal angle & 5.32 & 5.34 & 5.36 \\
\hline 5 & 7 & 16 & 4 & Unequal angle & 4.31 & 4.32 & 4.33 \\
\hline 6 & 7 & 20 & 4 & Equal angle & 4.9 & 4.91 & 4.92 \\
\hline 7 & 7 & 16 & 6 & Equal angle & 4.6 & 4.62 & 4.64 \\
\hline 8 & 7 & 20 & 6 & Unequal angle & 5.22 & 5.23 & 5.24 \\
\hline 9 & 9 & 16 & 4 & Equal angle & 4.19 & 4.21 & 4.23 \\
\hline 10 & 9 & 20 & 4 & Unequal angle & 4.78 & 4.8 & 4.82 \\
\hline 11 & 9 & 16 & 6 & Unequal angle & 4.52 & 4.53 & 4.54 \\
\hline 12 & 9 & 20 & 6 & Equal angle & 5.09 & 5.12 & 5.16 \\
\hline k1 & 4.87 & 4.46 & 4.61 & 4.76 & & & \\
\hline $\mathrm{k} 2$ & 4.77 & 5.07 & 4.92 & 4.77 & & & \\
\hline k3 & 4.66 & & & & & & \\
\hline $\mathrm{R}$ & 0.21 & 0.61 & 0.31 & 0.01 & & & \\
\hline
\end{tabular}

Checked the F value table, obtaining F0.05, 1, $2=18.5$, the F values of field number, single dose, dose rate and time in analysis of variance table were higher than F0.05, 1, 2, which 
were statistically significant $(\mathrm{P}<0.05)$, whereas the $\mathrm{F}$ value of ray angle was less than $\mathrm{F} 0.05$, 1,2 , which proved that the results were not statistically significant $(\mathrm{P}>0.05)$ by analysis of variance of orthogonal experiments.

By intuitive analyses from Table 4 , the ascending order of range values was $\mathrm{RA}=$ $0.21, \mathrm{RB}=0.61, \mathrm{RC}=0.31, \mathrm{RD}=0.01$, where the influencing order was $\mathrm{B}>\mathrm{C}>\mathrm{A}>\mathrm{D}$. The main influence factors were fractional dose and dose rate, followed by radiation field, and the influence of radiation angle was minimal.

Analysis of variance of Table 5 results showed that there were significant differences between different levels of factors $\mathrm{A}, \mathrm{B}$, and $\mathrm{C}(\mathrm{P}<0.05)$, and that factor $\mathrm{D}$ showed no significant difference $(\mathrm{P}>0.05)$. Combined with the optimal combination of $\mathrm{K}$ value $\mathrm{B} 1>\mathrm{C} 1>\mathrm{A} 3$, with factor $\mathrm{D}$ being equal or unequal angle, the influence on radiotherapy plan showed no significant difference, and considering the economic principle, the $\mathrm{D}$ factor being equal angle was more reasonable. The optimal combination scheme was $\mathrm{B} 1>\mathrm{C} 1>\mathrm{A} 3>\mathrm{D} 1$.

Table 5. Analysis of variance of caspase-3 protein expression quantity in beagle spinal cord neurons.
\begin{tabular}{lcccrc}
\hline Source & Factor & Mean square SS & Degree of freedom & Value F & Value P \\
\hline Radiation field (A) & 0.258 & 2 & 0.129 & 74.752 & 0.000 \\
Single dose (B) & 3.294 & 1 & 3.294 & 1906.421 & 0.000 \\
Dose rate (C) & 0.912 & 1 & 0.912 & 527.804 & 0.000 \\
Radiation angle (D) & 0.000 & 1 & 0.000 & 0.272 & 0.606 \\
\hline
\end{tabular}

\section{Expression quantity of caspase-3 mRNA in 7th-12th thoracic segments of spinal cord tissues}

The expression level of caspase-3 mRNA in each group of canine spinal neurons is shown in Figure 2 in detail, and the results were analyzed by analysis of variance of the orthogonal experiment.

Checked the $\mathrm{F}$ value table, obtaining F0.05, 1, $2=18.5$, the $\mathrm{F}$ values of field number, single dose, dose rate and time in analysis of variance table were higher than F0.05, 1, 2, which were statistically significant $(\mathrm{P}<0.05)$, whereas the $\mathrm{F}$ value of ray angle was less than $\mathrm{F} 0.05$, 1,2 , which proved that the results were not statistically significant $(\mathrm{P}>0.05)$ by analysis of variance of orthogonal experiments.

By intuitive analyses from Table 6 , the ascending order of range values was RA $=4.9$, $\mathrm{RB}=14.14, \mathrm{RC}=8.72$ and $\mathrm{RD}=0.45$, with the influencing order being $\mathrm{B}>\mathrm{C}>\mathrm{A}>\mathrm{D}$. The main influence factors were fractional dose and dose rate, followed by radiation field, and the influence of radiation angle was minimal.

Analysis of variance results of Table 7 showed that there were significant differences between different levels of factors $\mathrm{A}, \mathrm{B}$, and $\mathrm{C}(\mathrm{P}<0.05)$, and factor $\mathrm{D}$ has no significant difference $(\mathrm{P}>0.05)$. Together with the optimal combination of $\mathrm{K}$ value $\mathrm{B} 1>\mathrm{C} 1>\mathrm{A} 3$, the factor $\mathrm{D}$ being equal or unequal angle, the influence on radiotherapy plan was not significant, and considering the economic principle, the $\mathrm{D}$ factor being equal angle was more reasonable. The optimal combination scheme was $\mathrm{B} 1>\mathrm{C} 1>\mathrm{A} 3>\mathrm{D} 1$.

Immunohistochemical assay and SYBR Green I real-time quantitative RT-PCR were used to detect the expression quantity of caspase- 3 in spinal cord tissues, which produced the following results. The sequence of each factor influencing canine spinal biological safety was 
$\mathrm{B}>\mathrm{C}>\mathrm{A}>\mathrm{D}$, and the main influence factors were fractional dose and dose rate, followed by radiation field, and the influence of radiation angle was minimal. The two levels of radiation angle (angle, unequal angle) on spinal cord injury showed no statistical significance. With a single dose of $16 \mathrm{~Gy}$, dose rate of $4 \mathrm{~Gy} / \mathrm{min}$, field number of 9 , and radiation angle being equal, the expression of caspase- 3 in spinal cord neurons was lowest and the biological safety was highest, which provided the most optimal spinal IGRT scheme.

\begin{tabular}{|c|c|c|c|c|c|c|c|}
\hline Scheme No. & $\begin{array}{l}\text { Radiation field } \\
\text { No. }\end{array}$ & $\begin{array}{l}\text { Fractional dose } \\
\text { (Gy) }\end{array}$ & $\begin{array}{l}\text { Radiation angle } \\
\text { (Gy/min) }\end{array}$ & & $\begin{array}{c}\text { First group } \\
\text { caspase-3 mRNA }\end{array}$ & $\begin{array}{l}\text { Second group } \\
\text { caspase-3 mRNA }\end{array}$ & $\begin{array}{c}\text { Third group } \\
\text { caspase-3 mRNA }\end{array}$ \\
\hline 1 & 5 & 16 & 4 & Equal angle & 13.91 & 13.85 & 13.97 \\
\hline 2 & 5 & 20 & 4 & Unequal angle & 30.02 & 30.16 & 30.31 \\
\hline 3 & 5 & 16 & 6 & Unequal angle & 26.52 & 26.64 & 26.53 \\
\hline 4 & 5 & 20 & 6 & Equal angle & 37.78 & 36.99 & 37.92 \\
\hline 5 & 7 & 16 & 4 & Unequal angle & 12.06 & 12.17 & 12.46 \\
\hline 6 & 7 & 20 & 4 & Equal angle & 28.14 & 28.21 & 29.01 \\
\hline 7 & 7 & 16 & 6 & Equal angle & 18.47 & 18.05 & 18.68 \\
\hline 8 & 7 & 20 & 6 & Unequal angle & 35.21 & 35.91 & 36.04 \\
\hline 9 & 9 & 16 & 4 & Unequal angle & 11.98 & 12.03 & 12.14 \\
\hline 10 & 9 & 20 & 4 & Unequal angle & 19.55 & 19.69 & 19.47 \\
\hline 11 & 9 & 16 & 6 & Equal angle & 16.97 & 16.85 & 17.021 \\
\hline 12 & 9 & 20 & 6 & Equal angle & 33.13 & 33.54 & 33.77 \\
\hline k1 & 20.28 & 16.68 & 19.4 & 23.98 & & & \\
\hline $\mathrm{k} 2$ & 17.77 & 30.82 & 28.12 & 23.53 & & & \\
\hline k3 & 15.38 & & & & & & \\
\hline $\mathrm{R}$ & 4.90 & 14.14 & 8.72 & 0.45 & & & \\
\hline
\end{tabular}

Table 7. Analysis of variance of the expression quantity of caspase- 3 mRNA in beagle dogs' spinal cord neurons.

\begin{tabular}{llccrr}
\hline Source & Factor & Mean square SS & Degree of freedom & Value F & Value P \\
\hline A & No. of radiation field & 256.544 & 2 & 128.272 & 28.244 \\
B & Single radiation dose (Gy) & 1799.866 & 1 & 1799.866 & 396.311 \\
C & Dose rate (Gy/min) & 683.744 & 1 & 683.744 & 150.553 \\
D & Radiation angle & 1.773 & 1 & 1.773 & 0.390 \\
\hline
\end{tabular}

\section{DISCUSSION}

The principle of experimental animals states that those selected should be as close as possible in resemblance to the human spinal cord anatomy (Xilin et al., 2009), with the sequence being monkeys, dogs, pigs, rabbits, cats, rats, and others. The current literature (Xilin et al., 2009) notes that cells cultured are mostly used in the laboratory study of radiationinduced cell injury, while large mammals, relative to existing laboratory cells, have more advanced characters in cell injury induced by radiation. This research adopted adult, male purebred beagle dogs as the experimental animal. The beagle is an ideal internationally recognized experimental animal, where data reliability is high; the spinal anatomy of the adult beagle resembles that of humans, and the beagle's vertebral volume is larger than that of small animals, with the vertebral canal volume being large and the gap between spinal dural and osseous tissue being large, which can ensure the accuracy of sketching the target area and 
accurate radiotherapy. The composition of beagle's vertebral body, disc and spinal cord are very similar to that of humans, and the pathological degree of spinal cord injury and the clinical manifestations resemble closely the radiation injury of the spinal cord in clinical patients, which is of greater benefit to the study of pathological detection in laboratory (Chen et al., 2011). In addition, radiotherapy can reduce the immunity of experimental animals and thereby cause a decrease in resistance to infection and disease, while adult beagle dogs in this repect are far better than the smaller animals, which can guarantee the research proceeding smoothly (Dahele et al., 2011; Bujold et al., 2012).

Radiation myelopathy is also called radiation myelitis, which is a kind of disease that is triggered by the neuron denaturation and necrosis, while the spinal cord is subjected to irradiation combined with multiple factors. Radiation myelopathy relates to the normal spinal tissue subjected to high dose irradiation (Xilin et al., 2009). In conventional radiotherapy for spinal tumors, the spinal cord is subjected to equal irradiation dose as the target area. To avoid radiation myelitis from occurring, the radiation dose must be controlled in a certain range to protect the spinal cord. However, the dose may be inadequate and the dose distribution may not be ideal for tumor treatment, which may affect curative efficacy. Therefore, radiation injury of the spinal cord has become a limitation in the clinical use of IGRT.

A total radiation dose of $80 \mathrm{~Gy}$ was the choice for spinal IGRT in this study, which was based on previous study (Kliton et al., 2012) that determined the tolerance dose of the spinal cord in dogs, where the total radiotherapy dose of spinal IGRT was 50-80 Gy. In that study, beagles did not show double lower limb nerve symptoms of radiation myelitis, and neuron cell morphology was basically normal with no occurrence of obvious radiation myelitis. As the total radiotherapy dose of spinal IGRT was increased to 90-100 Gy, the dogs showed double lower limb neurological symptoms, even paraplegia, with most neuron cells losing normal morphology and the development of extensive neuronal apoptosis and serious radiation myelitis. Therefore, if the total radiotherapy dose of spinal IGRT is greater than $80 \mathrm{~Gy}$, biological safety of the spinal cord cannot be guaranteed.

In the late 1990s, with the rapid development of computer technology, medical imaging technology (such as CT, MRI), and image processing technology, radiotherapy techniques developed from the simple conventional 2D radiotherapy to sophisticated stereotactic radiotherapy, based on three-dimensional conformal radiotherapy technique, and there was a rapid development of three-dimensional conformal and intensity-modulated radiotherapy treatment and IGRT. The advent of IGRT boosted the effect of radiotherapy and greatly reduced the injury to normal tissue, so that the quality of life of patients was substantially improved. IGRT is regarded as a revolution in the history of radiation oncology by American and European fellow investigators, which is the mainstream of radiotherapy in twenty-first century. (Chang et al., 2012; Handsfield et al., 2012; Kliton et al., 2012; Kry et al., 2012; Park et al., 2012a,b; Wang et al., 2012; Zelefsky et al., 2012; Stoiber et al., 2013). IGRT of the spine is a four-dimensional radiation therapy technology, which has added the time factor to three-dimensional radiotherapy technology, fully considering the spinal metastatic tumor motion during treatment and the displacement error of the fractionated therapy, such as breathing and peristaltic movement, daily setup error, target area contraction caused by change in dose distribution and the influence on the treatment planning and other aspects of the situation, using advanced imaging equipment in patients before and during treatment. Accordingly, there is real-time monitoring of the spinal metastases and spinal cord, making it possible to adjust parameters correspondingly and to achieve accurate treatment. The advantage of IGRT in radiation phys- 
ics is obvious, because IGRT can achieve a consistent shape of high dose region and tumor target area and equal dose distribution at the three-dimensional level, and different doses can be distributed to different tumor target areas in one irradiation process.

However, determining IGRT planning must consider the single dose and dose rate, followed by radiotherapy field and radiation angle (Xu et al., 2012). How do we combine or choose the level of the above factors, so we can reach the optimal spinal cord biological safety? The problem needs a prompt solution. It is because of the existence of some differences between the IGRT advantage in radiation physics and the purpose of radiation biology that the radiological technology problems such as the economic and optimization scheme of spinal IGRT must be resolved by radiation biology results through real observations, the detection of spinal cord pathological changes, and expression of apoptosis factors (Xu et al., 2009; Deng et al., 2012; Qin et al., 2012; Tamura et al., 2012).

The expression of caspase-3 in spinal cord neurons was determined to optimize a high biological safety scheme for spinal IGRT. Caspase-3 expression in the spinal cord neurons was lowest with a single dose of $16 \mathrm{~Gy}$, dose rate of $4 \mathrm{~Gy} / \mathrm{min}$, field number of 9 , and ray angle being equal, which could be an optimal spinal IGRT scheme with high biological safety. In this study, spinal cord biological safety was the index for selecting the optimal treatment plan of spinal IGRT. The experimental results can provide experimental evidence for IGRT to improve the clinic dose rate and shorten the exposure time, so as to improve the local control of tumor.

\section{ACKNOWLEDGMENTS}

Research supported by the National Natural Science Foundation Project (\#81360276), the China Postdoctoral Science Foundation (\#2014M552566XB), the Xinjiang Uygur Autonomous Region Science and Technology Supporting Foundation in Xinjiang (\#2013911129), the Program for Cultivation of Innovation Talents of Science and Technology of the Xinjiang Uygur Autonomous Region (\#2013731013), and the Natural Science Foundation of Xinjiang Uygur Autonomous Region (\#2012211B34).

\section{REFERENCES}

Bujold A, Craig T, Jaffray D and Dawson LA (2012). Image-guided radiotherapy: has it influenced patient outcomes? Semin. Radiat Oncol. 22: 50-61.

Chang Z, Bowsher J, Cai J, Yoo S, et al. (2012). Imaging system QA of a medical accelerator, Novalis Tx, for IGRT per TG 142: our 1 year experience. J. Appl. Clin. Med. Phys. 13: 3754.

Chen G, Xu WL and Xilin BL (2011). Evaluation of radiation damages of vertebral bone cells after radiotherapy in dogs. Jiangsu Med. J. 37: 1882-1884.

Dahele M, Fehlings MG and Sahgal A (2011). Stereotactic radiotherapy: an emerging treatment for spinal metastases. Can. J. Neurol. Sci. 38: 247-250.

Deng J, Chen Z, Yu JB, Roberts KB, et al. (2012). Testicular doses in image-guided radiotherapy of prostate cancer. Int. J. Radiat. Oncol. Biol. Phys. 82: e39-e47.

Gerszten PC and Burton SA (2008). Clinical assessment of stereotactic IGRT: spinal radiosurgery. Med. Dosim. 33: 107-116.

Handsfield LL, Yue NJ, Zhou J, Chen T, et al. (2012). Determination of optimal fiducial marker across image-guided radiation therapy (IGRT) modalities: visibility and artifact analysis of gold, carbon, and polymer fiducial markers. $J$. Appl. Clin. Med. Phys. 13: 3976.

Kliton J, Agoston P, Major T and Polgar C (2012). Patient positioning using in-room kV CT for image-guided radiotherapy (IGRT) of prostate cancer. Magy. Onkol. 56: 193-198.

Kry SF, Jones J and Childress NL (2012). Implementation and evaluation of an end-to-end IGRT test. J. Appl. Clin. Med. Phys. 13: 3939. 
Manoranjan B, Salehi F, Scheithauer BW, Rotondo F, et al. (2010). Estrogen receptors alpha and beta immunohistochemical expression: clinicopathological correlations in pituitary adenomas. Anticancer Res. 30: 2897-2904.

Ministry os Science and Technology of People's Replubic of China (2006). Guidance Suggestion of Caring Laboratory Animals. The Ministry of Science and Technology of People's Republic of China, Beijing.

Park JC, Song B, Kim JS, Park SH, et al. (2012a). Fast compressed sensing-based CBCT reconstruction using BarzilaiBorwein formulation for application to on-line IGRT. Med. Phys. 39: 1207-1217.

Park SS, Yan D, McGrath S, Dilworth JT, et al. (2012b). Adaptive image-guided radiotherapy (IGRT) eliminates the risk of biochemical failure caused by the bias of rectal distension in prostate cancer treatment planning: clinical evidence. Int. J. Radiat. Oncol. Biol. Phys. 83: 947-952.

Qin YH, Huang L and Wang RZ (2012). Research situation and development of the image-guided radiotherapy technique. J. Xinjiang Med. Univ. 35: 298-300.

Stoiber EM, Schwarz M, Huber PE, Debus J, et al. (2013). Comparison of two IGRT correction strategies in postoperative head-and-neck IMRT patients. Acta Oncol. 52: 183-186.

Tamura Y, Torigoe T, Kukita K, Saito K, et al. (2012). Heat-shock proteins as endogenous ligands building a bridge between innate and adaptive immunity. Immunotherapy 4: 841-852.

Tsai JT, Lin JW, Chiu WT and Chu WC (2009). Assessment of image-guided CyberKnife radiosurgery for metastatic spine tumors. J. Neurooncol. 94: 119-127.

Wang L, Kielar KN, Mok E, Hsu A, et al. (2012). An end-to-end examination of geometric accuracy of IGRT using a new digital accelerator equipped with onboard imaging system. Phys. Med. Biol. 57: 757-769.

Xilin BL, Xu WL and Wang RZ (2009). The apoptosis of neurons after intensity modulated radiotherapy and conventional radiation therapy of the spine. J. Xinjiang Med. Univ. 32: 1645-1647.

$\mathrm{Xu}$ WL, Bai JP and Xilin BL (2009). The distribution of Fas, FasL and HSP70 in spinal cord after intensity modulated radiotherapy. J. Xinjiang Med. Univ. 32: 549-551.

Xu WL, Xilin BL and Liu H (2012). Spinal cord biological safety of image-guided radiation therapy versus conventional radiation therapy. Neural. Regen. Res. 7: 2755-2760.

Zelefsky MJ, Kollmeier M, Cox B, Fidaleo A, et al. (2012). Improved clinical outcomes with high-dose image guided radiotherapy compared with non-IGRT for the treatment of clinically localized prostate cancer. Int. J. Radiat. Oncol. Biol. Phys. 84: 125-129. 